\title{
Psychosocial and socio-economic factors in women and their relationship to obesity and regional body fat distribution
}

\author{
R Rosmond $^{1 *}$ and P Björntorp ${ }^{1}$ \\ ${ }^{1}$ Department of Heart and Lung Diseases, Sahlgrenska University Hospital, S-413 45 Göteborg, Sweden
}

BACKGROUND: Abdominal obesity, as well as psychosocial and socio-economic handicaps are risk factors for serious, prevalent diseases. Connections between these variables have been found in men.

OBJECTIVE: The principal aim of the present study was to analyse the associations between psychosocial and socioeconomic factors with body mass index (BMI) and the waist-to-hip circumference ratio (WHR) in women.

DESIGN: A cohort study of data derived from questionnaires.

SUBJECTS: 1137 women from a population sample of 1464 women born in 1956.

MEASUREMENTS: Occupational, social and leisure time conditions, smoking and alcohol habits, as well as height, weight and waist and hip circumferences.

RESULTS: BMI was associated with teetotalism and negatively to wine drinking. WHR correlated directly with cigarette smoking and negatively with consumption of wine and beer.

Both BMI and WHR, adjusted for each other and for smoking and alcohol, showed independent associations with low education, unemployment and problems at work when employed, as well as with little physical activity and much TVwatching. In addition, the WHR showed a negative, independent relationship to housing conditions.

CONCLUSION: These observations suggest psychosocial and socio-economic handicaps as well as a low physical activity in abdominally obese women. Similar observations have been made previously in men, but only with the WHR, suggesting an influence of obesity in these relationships in women only. Another interesting gender difference is the positive relationship between being married with BMI in men, as well as being divorced and living alone with the WHR in men only.

Keywords: psychosocial; socio-economic; BMI; WHR; women

\section{Introduction}

The relationship between obesity, measured as the body mass index (BMI, $\mathrm{kg} / \mathrm{m}^{2}$ ), and overall mortality, tends to show a U- or J-shaped risk curve for both sexes and all ages. ${ }^{1}$ In a recent prospective study, including both men and women, total mortality was higher in obese and underweight men, but not in women. ${ }^{2}$ However, a predominance of abdominal distribution of adipose tissue, measured as waist-to-hip circumference ratio (WHR) or other approximations of central body fat distribution, has shown a higher predictive power for various forms of health problems, than measurements of BMI. These health conditions include cardiovascular disease (CVD) ${ }^{3-6}$ non-insulin-dependent diabetes

*Correspondence: Roland Rosmond, Department of Heart and Lung Diseases, Sahlgrenska University Hospital, S-413 45 Göteborg, Sweden.

Received 4 June 1998; revised 10 August 1998; accepted

1 September 1998 mellitus (NIDDM), ${ }^{3,7-9}$ stroke, $^{3,4}$ breast cancer, ${ }^{10,11}$ and endometrial and ovarian cancer. ${ }^{12,13}$

Epidemiological studies have shown that psychosocial factors in modern, urbanised society may influence the development of diseases such as hypertension ${ }^{14}$ and atherosclerosis. ${ }^{15}$ In addition, animal experiments ${ }^{16-18}$ also clearly reflect how social subordination and psychoemotional distress impact on health via complex psycho-physiological mechanisms.

Recently, a cohort study of men from a population in Göteborg, Sweden, showed that subjects characterised by central body fat distribution, as indicated by an elevated WHR, were often out of work and frequently divorced. They also lived under poorer housing conditions, indicating a low socio-economic status, and had few leisure time activities, ${ }^{19}$ as well as psychiatric problems, such as traits of depression and anxiety. ${ }^{20}$ Personality disorders and impaired quality of life were also found to be more frequent among these individuals. $^{21,22}$ The objective of the present study was to evaluate the potential association between occupational and social factors and generalised obesity, as well as regional body fat distribution in women. 


\section{Subjects and methods}

\section{Study population}

The study population was selected from the National Population Register, Göteborg, Sweden, by systematic sampling and included all women born in 1956 on uneven days (first, 3rd, 5th, 7th, 9th etc.) of the month and living in Göteborg $(n=1464)$. Between January 1996 and May 1996 they were mailed a self-administered questionnaire. A total of 1137 women (77.7\%) responded to the questionnaire.

The study was approved by the Ethical Committee of the Medical Faculty of the University of Göteborg, and by the Swedish Data Inspection Board.

\section{Questionnaire design}

The survey questionnaire, which was formerly used in a cohort study of middle-aged men, has been described in detail in two previous reports. ${ }^{19,20}$ Briefly, the questionnaire consisted of 91 items within 10 categories (anthropometric measurements, previous and present diseases, present medication, history of working conditions, educational level, social situation, lifestyle factors, childhood and adolescence, smoking habits and alcohol intake). The questions were generally designed as closed-ended, that is, the respondents were asked to make a choice among the predetermined answers provided. A letter of introduction was enclosed with the questionnaire, stating the purpose of the study, research topic, sample size and sampling technique, instructions, and a statement about confidentiality and voluntary participation.

Education. The level of education was evaluated as: 1) Six-year elementary school, 2) Nine-year elementary school, 3) Folk high school, vocational school, 4) Upper secondary school (senior high school) and 5) College/university. The levels $1-3$ were categorised as a 'low educational level'.

Occupational variables. Current working conditions were investigated by a six-point scale: 1) Working at least $35 \mathrm{~h}$ week, 2) Working part-time $<35 \mathrm{~h}$ week, 3 ) Unemployed, 4) Early retirement, 5) Sickness pension and 6) Current sickness benefit. Those who answered the question by indicating $3-6$ on the scale were considered as 'out of work' and others as 'employed'.

Shift work was registered according to a 'yes-no' nominal scale.

The satisfaction with current work, colleagues and management were scored on the basis of a five-point scale for each item. Those who reported their satisfaction in group 4 ('satisfied') or group 5 ('very satisfied') were categorised as 'satisfied', and those who answered by indicating 1 ('not at all') or 2 ('poorly') on the scale were categorised as 'less satisfied.'
The influence on the work situation and work demands were examined using a five-point response scale for each item. A high degree of influence on work situation and work demands were defined as point 4 ('much') and point 5 ('very much') and a low degree as point 1 ('not at all') and point 2 ('hardly any').

Attempts to alter the work situation when having problems was quantified according to a five-point scale: 1) Never, 2) Seldom, 3) Occasionally, 4) Often and 5) Very often. Points 4 and 5 were classified as 'often' and points 1 and 2 as 'seldom'.

Social variables. The current civil status was graded as follows: 1) Unmarried, 2) Married or cohabit and 3) Divorced.

Housing conditions were placed in three categories: living in 1) Apartment, 2) Terrace house (row house) and 3) Private house, a rising scale of housing standard.

The ability to relax at home was ranked using a five-point scale. Frequent ability to relax at home was categorised as point 4 ('often') and point 5 ('very often') and less frequently as 1 ('never') and 2 ('seldom').

The feeling of time pressure was estimated according to a graphic seven-point rating scale, labelled at its ends with two extreme states: 1 ('not at all') to 7 ('very often'). A high degree of time pressure was defined as the two highest points on the scale and a low degree of time pressure as the two lowest.

Physical exercise, walking, gardening, visiting friends, reading, listening to music, dancing and watching TV were investigated by a five-point scale for each item. The responses never, seldom, occasionally, often and very often were given a score of 1, 2, 3, 4 and 5, respectively and ranked for each item. Frequent activities were classified as point 4 and point 5 and less frequent activities as 1 and 2 .

Life events (loss of a close relative, serious accident) within the past three years were recorded as 'yes' or 'no'.

Smoking and alcohol habits. The participants were categorised as those who had never smoked, exsmokers and current smokers, with the latter group subdivided by the number of cigarettes smoked daily, that is, 1) $1-4,2) 5-14,3) 15-24$ and 4) $>24$ cigarettes per day. In addition, the participants were classified as teetotallers and non-teetotallers; for nonteetotallers, the frequency of alcohol intake per week was measured as follows: The self-reported consumption of strong liquor was categorised into: 1) $0 \mathrm{cl}, 2$ ) $<37 \mathrm{cl}, 3) 37-75 \mathrm{cl}$ and 4) $>75 \mathrm{cl}$ per week. High consumption of strong liquor was defined as $>75 \mathrm{cl}$ per week. The consumption of wine was determined as: 1) $0 \mathrm{cl}$, 2) $<37 \mathrm{cl}, 3) 37-75 \mathrm{cl}$, 4) $76-150 \mathrm{cl}$ and 5) $>150 \mathrm{cl}$ per week. A high consumer of wine was defined as $>150 \mathrm{cl}$ wine per week. The consumption 
of beer was categorised into: 1) $0 \mathrm{cl}, 2)<33 \mathrm{cl}, 3$ ) $33-198 \mathrm{cl}$, 4) $199-396 \mathrm{cl}$ and 5) $>396 \mathrm{cl}$ per week. High consumption of beer was defined as $>396 \mathrm{cl}$ per week.

Anthropometric measurements. The women were asked, after careful instructions, to report their weight and height and to measure their waist and hip circumference. The circumferences were measured in the standing position in the morning after an overnight fast, the waist circumference at the level of the umbilicus and the hip circumference at the widest part over the buttocks. Based on the anthropometric measurements, the BMI was calculated as weight $/$ height $^{2}\left(\mathrm{~kg} / \mathrm{m}^{2}\right)$ and the WHR as the ratio between the waist and the hip circumferences.

\section{Statistical analysis}

Standard methods were used to calculate the descriptive statistics. Test of possible associations were first performed in a bivariate analysis with the Spearman's rho, where BMI and WHR were analysed as continuous variables, and psychosocial and socio-economic items as ordinal variables. All the associations identified by the bivariate analysis with a Spearman's rho $P$ value $\leq 0.150$ were then adjusted in a logistic regression model for the potential confounding effects of smoking (non-smoker/current smoker) and alcohol consumption (teetotallers/non-teetotallers). Because of the close interconnection between BMI and WHR (Spearman's rho $=0.36, P<0.001$ ), the anthropometric measurements were adjusted for each other. Each independent variable was included separately in the logistic regression model together with additional confounders. The dependent variables (BMI and WHR) were dichotomised by dividing each anthropometric measurement into four equal, ordered strata for every 25th percentile of each frequency distribution. Based on this stratification, a two-category model was assigned by designating individuals within the highest strata into one category and all others into another category for each anthropometric measurement (that is, $\mathrm{BMI} \geq 25.05$ vs $\mathrm{BMI}<25.05$ and $\mathrm{WHR} \geq 0.858 v s$ WHR $<0.858$ ).

All $P$-values are two-sided, and the level of statistical significance was considered to be $\alpha=0.05$. All data analyses were accomplished with SPSS for Windows, release 7.0, SPSS Inc., Chicago, IL.

\section{Results}

\section{Descriptive statistics}

Table 1 shows the mean values and standard deviations of the anthropometric measurements in the total study population. As indicated by the relatively narrow confidence intervals, these sample means seem to be sufficient estimators of the unknown (true) population means $\left(\mu_{\mathrm{i}}\right)$.

The distribution of registered variables concerning education and occupation per category of BMI and WHR is listed in Table 2. A total of $679(59.7 \%)$ of the respondents were employed and $170(14.9 \%)$ were at home. Low educational level, being out of work and shift work, seemed to be more frequent among respondents with $\mathrm{BMI} \geq 25.05$ compared to those with $\mathrm{BMI}<25.05(67.3 \%, 27.8 \%$ and $17.4 \%$, respectively). A similar trend was apparent among respondents with $\mathrm{WHR} \geq 0.858$. Among those working, a greater proportion of respondents reported a low satisfaction with work and colleagues, low degree of

Table 1 The anthropometric measurements. The values are shown as arithmetic means (s.d.) and 99\% confidence intervals (Cl)

\begin{tabular}{lcc}
\hline & Mean (s.d.) & $99 \% \mathrm{Cl}^{a}$ \\
\hline & & \\
Weight $(\mathrm{kg})$ & $64.6(11.5)$ & $63.8-65.5$ \\
Height $(\mathrm{cm})$ & $166.2(6.3)$ & $165.7-166.7$ \\
Body mass index $\left(\mathrm{kg} / \mathrm{m}^{2}\right)$ & $23.4(3.9)$ & $23.1-23.7$ \\
Waist circumference $(\mathrm{cm})$ & $80.1(11.1)$ & $79.2-80.9$ \\
Hip circumference $(\mathrm{cm})$ & $98.4(9.3)$ & $97.7-98.1$ \\
Waist-to-hip circumference ratio & $0.81(0.09)$ & $0.81-0.82$ \\
\hline
\end{tabular}

${ }^{\mathrm{a}} \mathrm{Cl}=$ Confidence interval $\left(\bar{X}_{\mathrm{i}} \pm 2.58 \times \mathrm{S} \hat{\mathrm{E}} \mathrm{X}_{\mathrm{i}}\right)$.

Table 2 Distribution of registered variables concerning education and occupation per category of body mass index (BMI) and waistto-hip circumference ratio (WHR). Figures within parentheses are percentages of total number of subjects in each category

\begin{tabular}{|c|c|c|c|c|}
\hline & $\begin{array}{c}B M I \geq 25.05(\mathrm{n}=281) \\
n(\%)\end{array}$ & $\begin{array}{c}B M I<25.05(\mathrm{n}=856) \\
n(\%)\end{array}$ & $\begin{array}{c}W H R \geq 0.858(\mathrm{n}=270) \\
n(\%)\end{array}$ & $\begin{array}{c}W H R<0.858(\mathrm{n}=867) \\
n(\%)\end{array}$ \\
\hline High-low educational level & $84(29.9)-189(67.3)$ & $410(47.9)-440(51.4)$ & $81(30.0)-183(67.8)$ & $418(48.2)-441(50.9)$ \\
\hline Employed-out of work & $197(70.1)-78(27.8)$ & $669(78.2)-171(20.0)$ & $187(69.3)-79(29.3)$ & $679(78.3)-170(19.6)$ \\
\hline Shift work-no shift work & $49(17.4)-210(74.7)$ & $128(15.0)-675(78.9)$ & $47(17.4)-203(75.2)$ & $130(15.0)-682(78.7)$ \\
\hline Satisfied-less satisfied with work & $175(62.3)-14(5.0)$ & $598(69.9)-27(3.2)$ & $174(64.4)-12(4.4)$ & $599(69.1)-29(3.3)$ \\
\hline $\begin{array}{l}\text { Satisfied - less satisfied with } \\
\text { colleagues }\end{array}$ & $193(68.7)-10(3.6)$ & $634(74.1)-8(0.9)$ & $186(68.9)-7(2.6)$ & $641(73.9)-11(1.3)$ \\
\hline $\begin{array}{l}\text { Satisfied-less satisfied with } \\
\text { management }\end{array}$ & $133(47.3)-32(11.4)$ & $459(53.6)-72(8.4)$ & $140(51.9)-21(7.8)$ & $452(52.1)-83(9.6)$ \\
\hline $\begin{array}{l}\text { High-low degree of influence } \\
\text { on work situation }\end{array}$ & $58(20.6)-85(30.2)$ & $232(27.1)-181(21.1)$ & $56(20.7)-75(27.8)$ & $234(27.0)-191(22.0)$ \\
\hline High-low degree of work demands & $157(55.9)-19(6.8)$ & $517(60.4)-42(4.9)$ & $140(51.9)-19(7.0)$ & $534(61.6)-42(4.8)$ \\
\hline $\begin{array}{l}\text { Often-seldom attempts to alter } \\
\text { work situation }\end{array}$ & $116(41.3)-26(9.3)$ & $451(52.7)-44(5.1)$ & $107(39.6)-18(6.7)$ & $460(53.1)-52(6.0)$ \\
\hline
\end{tabular}


Table 3 Distribution of registered variables concerning social status, smoking and alcohol habits per category of body mass index (BMI) and waist-to-hip circumference ratio (WHR). Figures within parentheses are percentages of total number of subjects in each category

$\begin{array}{cccc}B M I \\ 25.05(\mathrm{n}=281) & B M I<25.05(\mathrm{n}=856) & W H R \geq 0.858(\mathrm{n}=270) & W H R<0.858(\mathrm{n}=867) \\ n(\%) & n(\%) & n(\%) & n(\%)\end{array}$

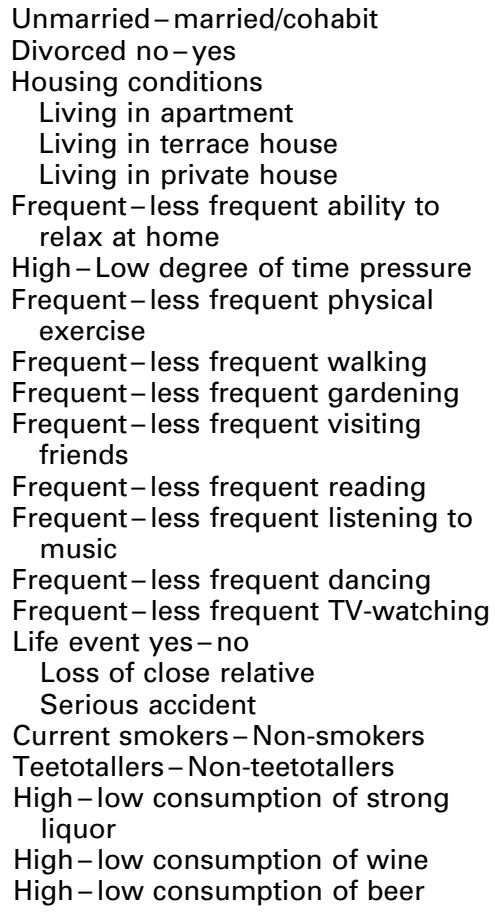

Frequent-less frequent walking

Frequent-less frequent gardening

Frequent-less frequent visiting friends

Frequent-less frequent reading

Frequent-less frequent listening to music

Frequent-less frequent dancing

Frequent-less frequent TV-watching

Life event yes - no

Loss of close relative

Serious accident

Current smokers-Non-smokers

Teetotallers - Non-teetotallers

High-low consumption of strong liquor

High-low consumption of wine

High-low consumption of beer

$46(16.4)-199$ (70.8)

$245(87.2)-33(11.7)$

$26(14.7)-601(70.2)$

$35(13.0)-200(74.1)$

$187(66.5)$

$29(10.3)$

$54(19.2)$

$193(68.7)-20(7.1)$

$119(42.3)-37(13.2)$

$36(12.8)-147(52.3)$

$125(44.5)-28(10.0)$

$46(16.4)-161(57.3)$

$121(43.1)-41(14.6)$

$155(55.2)-38(13.5)$

$136(48.4)-39(13.9)$

$7(2.5)-212(75.4)$

$158(56.2)-30(10.7)$

$113(40.2)-161(57.3)$

$35(12.5)-232(82.6)$

$101(35.9)-178(63.3)$

$41(14.6)-232(82.6)$

$3(1.1)-224(79.7)$

$18(6.4)-222(79.0)$

$5(1.8)-236(84.0)$

$727(84.9)-123(14.4) \quad 235(87.0)-32(11.9)$

$489(57.1)$
$125(14.6)$
$220(25.7)$
$551(64.4)-67(7.8)$

$418(48.8)-98(11.4)$ $192(22.4)-328(38.3)$

$432(50.5)-73(8.5)$

$160(18.7)-441(51.5)$

$371(43.3)-78(9.1)$

$478(55.8)-103(12.0)$

$410(47.9)-112(13.1)$

$20(2.3)-689(80.5)$

$383(44.7)-137$ (16.0)

$321(37.5)-518(60.5)$

$119(13.9)-713(83.3)$

$275(32.1)-568(66.4)$

$73(8.5)-778(90.9)$

$2(0.2)-758(88.6)$

$43(5.0)-739(86.3)$

$6(0.7)-764(89.3)$

$183(67.8)$
$30(11.1)$
$48(17.8)$
$176(65.2)-20(7.4)$

$114(42.2)-37(13.7)$

$26(9.8)-150(55.6)$

$132(48.9)-26(9.6)$

$50(18.5)-165(61.1)$

$98(36.3)-30(11.1)$

$141(52.2)-35(13.0)$

$128(47.4)-39(14.4)$

$9(3.3)-212$ (78.5)

$157(58.1)-29(10.7)$

111 (41.1) - 147 (54.4)

$37(13.7)-220(81.5)$

$106(39.3)-161(59.6)$

$33(12.2)-231(85.6)$

$2(0.7)-227(84.1)$

$12(4.4)-226$ (83.7)

5 (1.9)-232 (85.9)

$37(15.8)-600(69.2)$

$737(85.0)-124(14.3)$

$493(56.9)$

$124(14.3)$

$226(26.1)$

$568(65.5)-67$ (7.7)

$423(48.8)-98(11.3)$

$202(23.3)-325(37.5)$

$425(49.0)-75(8.7)$

$156(18.0)-437(50.4)$

$394(45.4)-89(10.3)$

$492(56.7)-106(12.2)$

$418(48.2)-112(12.9)$

$18(2.1)-689$ (79.5)

$384(44.3)-138(15.9)$

$323(37.3)-532(61.4)$

$117(13.5)-725(83.5)$

$270(31.1)-585$ (67.5)

$81(9.3)-779(89.9)$

$3(0.3)-755(87.1)$

$50(5.8)-735(84.8)$ $6(0.7)-768(88.6)$ influence on work situation and low degree of work demands with infrequent attempts to alter work situation within the same categories.

Table 3 presents the distribution of registered variables concerning social status, smoking and alcohol habits, per category of BMI and WHR. Respondents with $\mathrm{BMI}<25.05$ and $\mathrm{WHR}<0.858$ seemed to live more often in private houses, while respondents with $\mathrm{BMI} \geq 25.05$ and $\mathrm{WHR} \geq 0.858$ lived more often in apartments. Among the latter groups, a greater proportion of respondents reported a high degree of time pressure, less frequent physical exercise and frequent TV watching. Cigarette smoking seemed to be more common among respondents with WHR $\geq 0.858$ compared to those with WHR $<0.858$.

\section{Bivariate analysis}

Teetotalism was positively related to BMI and, in addition, consumption of wine was inversely significantly correlated to BMI (Table 4). WHR correlated directly with cigarette smoking and negatively with consumption of wine and beer.

\section{Multivariate analyses}

Correlation analyses identified 14 variables for inclusion into the multivariate analysis of BMI (Spearman's rho $P \leq 0.150$ ), and 17 variables for the analysis of WHR. These variables are listed in Table 5 and
Table 4 Spearman's rho $(\rho)$ and $P$-values for the correlations between the anthropometric measurements and smoking and alcohol habits

\begin{tabular}{|c|c|c|c|c|}
\hline & \multicolumn{2}{|c|}{$B M I$} & \multicolumn{2}{|c|}{ WHR } \\
\hline & $\rho$ & $P$-values & $\rho$ & $P$-values \\
\hline Cigarette smoking & 0.04 & $>0.200$ & 0.10 & $<0.001$ \\
\hline Teetotallers-Non-teetotallers & 0.09 & 0.002 & 0.03 & $>0.200$ \\
\hline Consumption of strong liquor & 0.02 & $>0.200$ & 0.02 & $>0.200$ \\
\hline Consumption of wine & -0.09 & 0.007 & -0.12 & $<0.001$ \\
\hline Consumption of beer & -0.04 & 0.167 & -0.13 & $<0.001$ \\
\hline
\end{tabular}

$\mathrm{BMI}=$ body mass index; WHR = waist-to-hip circumference ratio.

Table 6, respectively. To assess the predictive power of the psychosocial and socio-economic variables in relation to categories of BMI and WHR, a logistic regression analysis was performed. Table 5 illustrates such an analysis with a two-group model of BMI, adjusted for the WHR, smoking and alcohol. Out of work and watching TV were positively related to BMI ( $\beta=0.46$ and $\beta=0.31$, respectively). Educational level, employment, satisfaction with management, influence on work situation and attempts to alter work situation, as well as physical exercise and walking, were significantly negatively associated with BMI.

Table 6 shows a similar analysis with a two-group model of WHR, adjusted for BMI, smoking and 
Table 5 The regression coefficients $(\beta)$, odds ratios $(\mathrm{OR})^{\mathrm{a}}$ and corresponding $P$-values of the psychosocial and socio-economic variables in relation to categories of body mass index (BMI), with simultaneous adjustments for waist-to-hip circumference ratio (WHR), smoking and alcohol

\begin{tabular}{lrcr}
\hline & $B M I \geq 25.05 \mathrm{vs} B M I<25.05$ & $P$-values \\
\hline & $\beta$ & $\mathrm{OR}$ & \\
Educational level & -0.12 & 0.88 & 0.019 \\
Employed & -0.46 & 0.63 & 0.005 \\
Out of work & 0.46 & 1.58 & 0.005 \\
Shift work & 0.16 & 1.17 & $>0.200$ \\
Satisfaction with & -0.15 & 0.86 & 0.079 \\
$\quad$ work & & & \\
Satisfaction with & -0.16 & 0.85 & 0.032 \\
$\quad$ management & -0.27 & 0.76 & $<0.001$ \\
Influence on work situation & -0.22 & 0.80 & 0.013 \\
Attempts to alter work & & & \\
$\quad$ situation & -0.16 & 0.85 & 0.054 \\
Housing conditions & 0.14 & 1.15 & 0.096 \\
Ability to relax at home & 0.01 & 1.01 & $>0.200$ \\
Time pressure & -0.23 & 0.79 & 0.002 \\
Physical exercise & -0.18 & 0.84 & 0.036 \\
Walking & 0.31 & 1.37 & 0.003 \\
Watching TV & & \\
\hline
\end{tabular}

${ }^{a}$ The natural logarithm e (2.718) raised to the value of the regression coefficient $(\beta)$.

Table 6 The regression coefficients $(\beta)$, odds ratios $(O R)^{\mathrm{a}}$ and corresponding $P$-values of the psychosocial and socio-economic variables in relation to categories of waist-to-hip circumference ratio (WHR) with simultaneous adjustments for body mass index (BMI), smoking and alcohol.

\begin{tabular}{lccr}
\hline & WHR $\geq 0.858$ vs $W H R<0.858$ & $P$-values \\
\hline & $\beta$ & OR & \\
Educational level & -0.16 & 0.85 & 0.002 \\
Employed & -0.59 & 0.55 & $<0.001$ \\
Out of work & 0.59 & 1.81 & $<0.001$ \\
Shift work & 0.20 & 1.22 & $>0.200$ \\
Satisfaction with work & -0.08 & 0.92 & $>0.200$ \\
Satisfaction with & 0.04 & 1.04 & $>0.200$ \\
$\quad$ management & -0.20 & 0.81 & 0.008 \\
$\quad$ Influence on work & & & \\
$\quad$ situation & -0.14 & 0.87 & 0.095 \\
Work demands & -0.18 & 0.83 & 0.007 \\
Attempts to alter work & & & \\
$\quad$ situation & 0.27 & 1.30 & 0.197 \\
Unmarried - married/ & & & \\
$\quad$ cohabit & 0.21 & 1.24 & $>0.200$ \\
Divorced no - yes & -0.18 & 0.83 & 0.022 \\
Housing conditions & -0.06 & 0.94 & 0.195 \\
Time pressure & -0.38 & 0.68 & $<0.001$ \\
Physical exercise & -0.07 & 0.93 & $>0.200$ \\
Gardening & 0.23 & 1.26 & 0.008 \\
Watching TV & 0.25 & 1.28 & 0.117 \\
Loss of close relative & &
\end{tabular}

${ }^{a}$ The natural logarithm e (2.718) raised to the value of the regression coefficient $(\beta)$.

alcohol. Being out of work and watching TV showed positive significant independent relationships to WHR $(P<0.001$ and $P=0.008$, respectively). Negative independent associations remained for educational level, employment, influence on work situation, attempt to alter work situation, housing conditions and physical exercise.

\section{Discussion}

In this study of 40-year old women, psychosocial and socio-economic factors were examined in relation to the anthropometric measurements of BMI and WHR. Measurements were performed by the participants after careful instructions, and have previously been found to give sufficiently accurate results. ${ }^{23-26}$ The BMI and WHR were subdivided into subgroups on the basis of the quartiles of their distribution. This resulted in a borderline between groups of 25.05 for BMI and 0.858 for WHR. A recent consensus ${ }^{27}$ has set a BMI of 25 as the borderline between normal and overweight. In women, risk of development of CVD, NIDDM and premature mortality increases at a WHR of about $0.85{ }^{4,7}$ The cut-offs for BMI and WHR in this work may therefore be considered as clinically applicable.

The BMI is an estimation of total body fat mass, while the WHR contains other information, including distribution of body fat masses. Both these variables are expected to be regulated differently and were therefore adjusted for each other in the multivariate analyses.

Tobacco smoking was related to the WHR, but not to the BMI, confirming several other reports, ${ }^{28-31}$ including a previous study of older women from the same city. ${ }^{32}$ Women with elevated BMI were more often teetotallers than those with a low BMI. BMI was also negatively related to wine consumption, while beer and strong liquor did not show any significant relationships to the BMI. The WHR showed negative associations to wine and beer, and no significant connection with strong liquor. This is in sharp contrast to a previous study in older women from Göteborg, where a significant, positive relationship was found between the WHR and the consumption of strong liquor. ${ }^{32}$ Several explanations seem possible for this inconsistency. First, drinking wine is now more common in Sweden than 25 years ago when the previous study was performed, where consumption of strong liquor was higher in relative terms. It may also be that women in the age $43-65$ y drink more strong alcohol than women at the age of $40 \mathrm{y}$. A third, and perhaps more likely explanation may be that alcohol consumption was underreported, a wellknown phenomena, particularly as far as consumption of strong liquor is concerned.

The association between alcohol and the WHR is a controversial issue, some authors reporting such a connection, ${ }^{33,34}$ while others do not find such a relationship. ${ }^{35,36}$ Incorrect data, due to underreporting, might be an explanation of this confusion. Some studies suggest that a minimum level of alcohol intake is necessary to discover the association. ${ }^{32}$ Socially adapted alcoholics have not only a higher WHR than teetotallers, but also an enlargement of visceral fat mass measured by computed tomography (CT). ${ }^{37}$ Furthermore, ongoing studies in our laboratory, where a history of alcohol intake was obtained 
with more sophisticated methods than are used here, indicate a strong relationship between alcohol intake and the WHR. Moreover, the WHR correlates positively with liver tests indicating alcohol consumption. $^{34}$ In summary, it seems likely that alcohol consumption is associated directly with the WHR, and that the lack of such a relationship in this and other ${ }^{35,36}$ studies, might be due to underreporting in questionnaires completed at home.

Educational level and employment showed significant, independent predictive power to the BMI. Furthermore, low satisfaction with the work management, small possibilities to influence the working situation and attempts to alter the work situation, were also significant predictors of obese women $(\mathrm{BMI} \geq 25.05)$. When examining the associations with the WHR instead, essentially identical results were found. All the calculations were adjusted for the potential influence of smoking and alcohol, and the BMI and WHR mutually adjusted. Differences in various relationships between the BMI and WHR were, however, also found. These included a significant negative association between the WHR and housing conditions, which was only borderline significance for BMI $(\beta=-0.16, P=0.054)$. Of note is the observation that being divorced was associated with the WHR in bivariate analysis only, not in multivariate calculations.

In relation to the previous study on older women, ${ }^{32}$ the following points are of note. The difference in results in alcohol consumption has been discussed above. Smoking shows, however, a consistent positive relationship to the WHR in both studies, and so does a low educational level. Housing conditions, an indirect measurement of economic status, showed negative associations and a low level of education and unemployment, positive associations with the BMI and WHR, suggesting a low socio-economic condition in the present work, in agreement with the previous observations. $^{32}$

The results from this study of women should also be compared with the similar study of men, ${ }^{19}$ utilising the same techniques. The similarities between men and women in these studies are the relationship between the BMI and low education, and between the WHR and smoking, low education, being out of work and having problems at work. ${ }^{19}$ The differences are more striking, consisting of the positive relationship in men between the BMI and being married, which is lacking in women. Furthermore, the strong independent relationship between WHR and being divorced in men, ${ }^{19}$ was only found as a weaker association in bivariate analysis in women, disappearing in multivariate analyses.

\section{Conclusions}

In summary, the results of this study of women may be interpreted as follows. BMI, indicating obesity, was associated with being more frequently a teetotaller and with less consumption of wine, low education, and frequent unemployment, problems at work when employed, little exercise, but much TV-watching. The WHR showed essentially the same associations. An elevated WHR is an index of centralisation of body fat. The characteristics then might be interpreted to mean that these characteristics are frequently found in women with abdominal obesity.

The WHR showed additional associations, not shared by the BMI, including smoking and, probably, lower housing standards. Since smokers are often lean, the lack of association with BMI might be expected. Poorer housing standards seem likely to be an index of a lower socio-economic status.

In short, women with abdominal obesity (elevated BMI and WHR) in this study, seem to be characterised by psychosocial and socio-economic handicaps in education and unemployment, and have problems at work, as well as a low degree of physical activity with much TV-watching. Women with abdominal distribution of fat without obesity are often smokers.

In comparisons with men, similar psychosocial and socio-economic problems are apparent, but only with centralisation of body fat. Interestingly, men seem to be more frequently married with increasing BMI except in the highest $20 \%{ }^{19}$ Furthermore, men living alone and/or being divorced were found to often have a centralisation of body fat without a relationship to BMI.

Psychosocial and socio-economic handicaps are then consistently associated with a centralisation of body fat in both women and men. In women, but not in men, this seems to be coupled with obesity. It is difficult to interpret this gender difference, but it might be speculated that women are more stigmatised by obesity than men, and therefore are exposed to more problems in their employment.

We have previously suggested ${ }^{38}$ that an endocrine abnormality, consisting of a hyperactivity of the hypothalamic-pituitary-adrenal (HPA) axis, might be the cause of centralisation of body fat, due to an increased cortisol secretion, ${ }^{39,40}$ as clearly seen in Cushing's syndrome. One might speculate that psychosocial and socio-economic handicaps, as seen in both genders, might lead to a depressive stressreaction, similar to that described in experimental animals. ${ }^{41}$ The traits of depression and anxiety found repeatedly in cohorts of both men and women, ${ }^{19-22,32,42}$ might be part of such a reaction, which then would be expected to be followed by an activation of the HPA axis. ${ }^{43}$ This interpretation is strongly supported by studies of other primates, which when stressed by psychosocial manipulations, develop a submissive, depressive reaction and signs of a hyperactive HPA axis with visceral fat accumulation. ${ }^{44,45}$ It seems likely that tobacco smoking exaggerates the centralisation of fat through similar mechanisms, because smoking is followed by increased cortisol secretion. ${ }^{46}$ Alcohol consumption 
has the same effects, ${ }^{47}$ but the consistency of an association between alcohol and the WHR is not as robust as that with depression and smoking, and needs further studies with more refined methodology.

\section{Acknowledgements}

The authors thank Anna Nilsson who assisted in the data collection. The study was supported by the Swedish Medical Research Council (K97-19X00251-35A).

\section{References}

1 Waaler HT. Height, weight and mortality. The Norwegian experience. Acta Med Scand 1984; 215 (Suppl. 679): S1-S56.

2 Seidell JC, Verschuren WMM, van Leer EM, Kromhout D. Overweight, underweight and mortality. A prospective study of 48287 men and women. Arch Intern Med 1996; 156: 958-963

3 Larsson B, Svärdsudd K, Welin L, Wilhelmsen L, Björntorp P, Tibblin G. Abdominal adipose tissue distribution, obesity, and risk of cardiovascular disease and death: 13 year follow up of participants in the study of men born in 1913. BMJ 1984; $\mathbf{2 8 8}$ : $1401-1404$.

4 Lapidus L, Bengtsson C, Larsson B, Pennert K, Rybo E, Sjöström L. Distribution of adipose tissue and risk of cardiovascular disease and death: a 12 year follow up of participants in the population study of women in Gothenburg, Sweden. BMJ 1984; 289: $1257-1261$.

5 Stokes J, Garrison RJ, Kannel WB. The independent contributions of various indices of obesity to the 22 -year incidence of coronary heart disease: the Framingham Heart Study. In: Vague J, Björntorp P, Guy-Grand B, Rebuffé-Scrive M, Vague P (eds). Metabolic complications of human obesities. 1985, Elsevier Science Publishers (Biomedical Division): New York, pp 49-57.

6 Donahue RP, Abbott RD, Bloom E, Reed DM, Yano K. Central obesity and coronary heart disease in men. Lancet 1987; 1: 821-824.

7 Ohlsson L-O, Larsson B, Svärdsudd K, Welin L, Eriksson H, Wilhelmsen L, Björntorp P, Tibblin G. The influence of body fat distribution on the incidence of diabetes mellitus. A 13.5 years of follow-up of the participants in the study of men born in 1913. Diabetes 1985; 34: 1055-1058.

8 Bergstrom RW, Newell-Morris LL, Leonetti DL, Shuman WP, Wahl PW, Fujimoto WY. Association of elevated fasting Cpeptide level and increased intra-abdominal fat distribution with development of NIDDM in Japanese-American men. Diabetes 1990; 39: 104-111.

9 Haffner SM, Stern MP, Mitchell BD, Hazuda HP, Patterson JK. Incidence of type II diabetes in Mexican Americans predicted by fasting insulin and glucose levels, obesity, and body-fat distribution. Diabetes 1990; 39: 283-288.

10 Folsom AR, Kaye SA, Prineas RJ, Potter JD, Gapstur SM, Wallace RB. Increased incidence of carcinoma of the breast associated with abdominal adiposity in postmenopausal women. Am J Epidemiol 1990; 131: 794-803.

11 Bruning PF, Bonfrèr JMG, Hart AAM, van Noord PAH, van der Hoeven H, Collette HJA, Battermann JJ, De Jong-Bakker M, Nooijen WJ, De Waard F. Body measurements, estrogen availability and the risk of human breast cancer: a case-control study. Int J Cancer 1992; 51: 14-19.

12 Lapidus L, Helgesson Ö, Merck C, Björntorp P. Adipose tissue distribution and female carcinomas. A 12-year followup of participants in the population study of women in Gothenburg, Sweden. Int J Obes 1988; 12: 361-368.
13 Schapira DV, Kumar NB, Lyman GH, Cavanagh D, Roberts WS, LaPolla J. Upper-body fat distribution and endometrial cancer risk. JAMA 1991; 266: 1808-1811.

14 James SA. Psychosocial precursors of hypertension: a review of the epidemiologic evidence. Circulation 1987; 76 (Suppl. I): S60-S66.

15 Williams RB. Psychological factors in coronary artery disease: epidemiologic evidence. Circulation 1987; 76 (Suppl. I): S117-S123.

16 Hallbäck M. Consequence of social isolation on blood pressure, cardiovascular reactivity and design in spontaneously hypertensive rats. Acta Physiol Scand 1975; 93: $455-465$.

17 Hamm TE, Kaplan JR, Clarkson TB, Bullock BC. Effects of gender and social behavior on the development of coronary artery atherosclerosis in cynomolgus macaques. Atherosclerosis 1983; 48: $221-233$.

18 Adams MR, Kaplan JR, Clarkson TB, Koritnik DR. Ovariectomy, social status and atherosclerosis in cynomolgus monkeys. Arteriosclerosis 1985; 5: 192-200.

19 Rosmond R, Lapidus L, Björntorp P. The influence of occupational and social factors on obesity and body fat distribution in middle-aged men. Int J Obes 1996; 20: 599-607.

20 Rosmond R, Lapidus L, Mårin P, Björntorp P. Mental distress, obesity and body fat distribution in middle-aged men. Obes Res 1996; 4: 245-252.

21 Rosmond R, Wilhelmsen L, Björntorp P. Personality disorders, obesity and body fat distribution in middle-aged men [Abstract]. Int J Obes 1996; 20 (Suppl. 4): S107.

22 Rosmond R, Wilhelmsen L, Björntorp P. Quality of life, obesity and body fat distribution in middle-aged men [Abstract]. Int J Obes 1996; 20 (Suppl. 4): S107.

23 Stunkard AJ, Albaum JM. The accuracy of self-reported weights. Am J Clin Nutr 1981; 34: 1593-1599.

24 Stewart AL. The reliability and validity of self-reported weight and height. J Chron Dis 1982; 35: 295-309.

25 Kaye SA, Folsom AR, Jacobs DR, Hughes GH, Flack JM. Psychosocial correlates of body fat distribution in black and white young adults. Int J Obes 1993; 17: 271-277.

26 Nakatsuka H, Satoh H, Watanabe T, Ida Y, Nishigouri M, Ikeda M. The reproducibility of reported height and body weight in repeated questionnaire surveys. Int J Obes 1995; 19: $50-56$.

27 World Health Organisation Obesity. Preventing and managing the global epidemic. Report of a WHO consultation on Obesity. WHO: Geneva, 3-5 June 1997, WHO/NUT/ NCD/98.1, 1998.

28 Shimokata H, Muller DC, Andres R. Studies in the distribution of body fat. III. Effects of cigarette smoking. JAMA 1989; 261: $1169-1173$.

29 Barrett-Connor E, Khaw K-T. Cigarette smoking and increased central adiposity. Ann Intern Med 1989; 111: $783-787$.

30 den Tonkelaar I, Seidell JC, van Noord PAH, Baanders-van Halewijn EA, Ouwehand IJ. Fat distribution in relation to age, degree of obesity, smoking habits, parity and estrogen use: a cross-sectional study in 11825 Dutch women participating in the Dom-project. Int J Obes 1990; 14: 753-761.

31 Seidell JC, Cigolini M, Deslypere JP, Charzewska J, Ellsinger BM, Cruz A. Body fat distribution in relation to physical activity and smoking habits in 38-year-old European men The European Fat Distribution Study. Am J Epidemiol 1991; 133: $257-265$.

32 Lapidus L, Bengtsson C, Hällström T, Björntorp P. Obesity, adipose tissue distribution and health in women - results from a population study in Gothenburg, Sweden. Appetite 1989; 12: $25-35$.

33 Troisi RJ, Weiss ST, Segal MR, Cassano PA, Vokonas PS, Landsberg L. The relationship of body fat distribution to blood pressure in normotensive men: The normative aging study. Int $J$ Obes 1990; 14: 515-525. 
34 van Barneveld T, Seidell JC, Traag N, Hautvast JGAJ. Fat distribution and gamma-glutamyl transferase in relation to serum lipids and blood pressure in 38-year old Dutch males. Eur J Clin Nutr 1989; 43: 809-818.

35 Haffner SM, Valdez R, Morales PA, Mitchell BD, Hazuda, HP, Stern MP. Greater effect of glycemia on incidence of hypertension in women than in men. Diabetes Care 1992; 15: $1277-1284$.

36 Selby JV, Newman B, Quesenberry CP, Fabsitz RR, Carmelli $\mathrm{D}$, Meaney FJ, Slemenda C. Genetic and behavioral influences on body fat distribution. Int J Obes 1990; 14: 593-602.

37 Kvist H, Hallgren P, Jönsson L, Pettersson P, Sjöberg C, Sjöström L, Björntorp P. Distribution of adipose tissue and muscle mass in alcoholic men. Metabolism 1993; 42: $569-573$.

38 Björntorp P. Visceral obesity: a 'Civilization Syndrome'. Obes Res. 1993; 1: 206-222.

39 Mårin P, Darin N, Amemiya T, Andersson B, Jern S, Björntorp P. Cortisol secretion in relation to body fat distribution in obese premenopausal women. Metabolism 1992; 41: $882-886$.

40 Ljung T, Andersson B, Bengtsson B- $\AA$, Björntorp P, Mårin P. Inhibition of cortisol secretion by dexamethasone in relation to body fat distribution: a dose-response study. Obes Res 1996; 4: $277-282$.
41 Henry JP, Stephens PM. Stress, health, and the social environment. A sociobiological approach to medicine. Springfield: New York, 1977.

42 Rosmond R, Björntorp P. Psychiatric ill-health of women and its relationship to obesity and body fat distribution. Obes Res 1998; 6: $338-345$.

43 Linkowski P, Mendlewicz J, Leclercq R, Brasseur M, Hubain P, Golstein J, Copinschi G, van Cauter E. The 24-hour profile of adrenocorticotropin and cortisol in major depressive illness. $J$ Clin Endocrinol Metab 1985; 61: 429-438.

44 Shively C, Kaplan J. Effects of social factors on adrenal weight and related physiology of Macaca Fascicularis. Physiol Behav 1984; 33: 777-782.

45 Jayo JM, Shively CA, Kaplan JR, Manuck SB. Effects of exercise and stress on body fat distribution in male cynomolgus monkeys. Int J Obes 1993; 17: 597-604.

46 Gossain VV, Sherma NK, Srivastava L, Michelakis AM, Rovner DR. Hormonal effects of smoking. II: effects on plasma, cortisol, growth hormone, and prolactin. Am J Med Sci 1986; 291: 325-327.

47 Cicero TJ. Sex differences in the effects of alcohol and other psychoactive drugs on endocrine function. In: Israel Y, Kalant O, Kalant $\mathrm{H}$ (eds). Research Advances in Alcohol and Drug Problem. Plenum: New York, 1980: $544-593$. 